\title{
A Study on the Effect of Isometric Quadriceps Activation and Vastus Medialis Obliquus Strengthening in Decreasing Q-Angle among Young Females
}

\author{
Santhi Venkatapathy ${ }^{1}$, Rajesh Bhargavan ${ }^{2}$ \\ ${ }^{1}$ Department of Anatomy, Sri Lakshmi Narayana Institute of Medical Sciences, Pondicherry, (Bharath Institute of \\ Higher Education \& Research, Chennai, Tamil Nadu, India). ${ }^{2}$ Department of Anatomy, Sri Lakshmi Narayana Institute \\ of Medical Sciences, Pondicherry, (Bharath Institute of Higher Education \& Research, Chennai, India).
}

\section{ABSTRACT}

\section{BACKGROUND}

Females are more prone for lateral displacement of patella than males due to increased Q-angle $\left(15-18^{\circ}\right)$ in them compared to males $\left(12-15^{\circ}\right)$. In a normal state, lateral displacement is prevented by geometry of the joint and by the passive stabilizers. Even though contraction of the quadriceps tends to displace the patella laterally, vastus medialis oblique (VMO) acts medially and posteriorly as much as it acts proximally, and so its tension helps in resisting the $\mathrm{Q}$ angle effect. There are two procedures in common practice to reduce Q-angle and thereby to prevent lateral displacement of patella- either through vastus medialis oblique (VMO) strengthening or by isometric quadriceps activation (quadriceps muscle strengthening). We wanted to compare the effects of isometric quadriceps activation and VMO strengthening in reducing $Q$ angle in a group of young females.

\section{METHODS}

A non-randomized, two group, pre-test, post-test assessment of Q-angle was done. Twenty healthy females of 18-20 age group were selected and randomly divided into two groups. Isometric quadriceps activation and VMO strengthening was done for 4 weeks. Q-angles were measured before and after the strengthening exercise using a long arm goniometer.

\section{RESULTS}

The mean q angle before treatment was 21. (minimum 20 and maximum 23). While after the treatment, $\mathrm{q}$ angles were significantly reduced in both the groups and mean $\mathrm{q}$ angle was 16.3 .

\section{CONCLUSIONS}

Both the isometric quadriceps activation and VMO strengthening reduced Q-angle significantly and there was no significant difference between the two procedures. Results of this study help the physiotherapist in choosing the exercise for the management of patellofemoral pain and lateral displacement of patella.

\section{KEY WORDS}

Q Angle, Quadriceps Femoris, Vastus Medialis Obliquus, Patello-Femoral Pain.
Corresponding Author: Dr. Rajesh Bhargavan, Professor, Department of Anatomy, Sri Lakshminarayana Institute of Medical Sciences, Kudapakkam P. O., Pondicherry, India.

E-mail: anat_rajesh@rediffmail.com

DOI: $10.14260 /$ jemds/2020/208

Financial or Other Competing Interests: None.

How to Cite This Article:

Venkatapathy S, Bhargavan R. A study on the effect of isometric quadriceps activation and vastus medialis obliquus strengthening in decreasing Q-angle among young females. J. Evolution Med. Dent. Sci. 2020;9(12):965-968, 10.14260/jemds/2020/208

Submission 04-09-2017, Peer Review 03-03-2020,

Acceptance 09-03-2020, Published 23-03-2020.

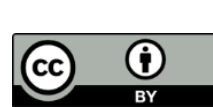




\section{BACKGROUND}

The "quadriceps" include the vastus medialis oblique (VMO), vastus intermedius, vastus lateralis and rectus femoris. Quadriceps Angle (Q-angle) is the angle formed between the intersection of the axis of quadriceps extensor mechanism and patellar tendon. Thus Q-angle is formed in the frontal plane by two line segments- from tibial tubercle to the middle of the patella and from the middle of the patella to the ASIS. The Qangle in adult is typically 15 degrees. Weakness of quadriceps muscles may adversely affect the patellofemoral mechanism. Quadriceps strengthening is most commonly recommended as the quadriceps muscles play a significant role in patellar movement. Vastus medialis oblique muscle serves to extend the knee as well as function as a major medial stabilizer for the patella. During knee extension the VMO pulls the patella medially due to its orientation relative to the patella. Anatomically, a woman's knee is made with a naturally greater Q-angle between the femur and the tibia, predisposing it to greater stress due to the torsion applied between the femur and the tibia. The increased Q-angle causes the quadriceps to pull on the patella, which will encourage it to displace. The patella/patellar tendon ratio should be nearly equal. When the patellar tendon is excessively long, a high-riding patella exists and lateral displacement of the patella may occur easily. The increased Q- angle also causes the feet to be more pronated and flattened.(1)

It was observed that young and physically active females are more prone to patellar dislocation - especially with minimal trauma; when they twist the flexed knee with the foot fixed to the ground, for example, during sporting activities. Patella or knee cap instability is the most common recurrent symptom reported in literature. It may be associated with abnormal shape of the knee joint bones, weakness of the muscles around the hip or knees or tightness of soft tissues on the outside of the knee. Factors that contribute to an increased Q-angle in women include.(1-4) a wider pelvis, increased femoral ante version, increased knee valgus, external tibial torsion, increased ligamentous laxity, hyper pronation of the foot, patella alta, a tight lateral patellar retinaculum and a hypoplastic or weak vastus medialis oblique. The combination of increased femoral ante version, external tibial torsion, and hyper pronation of the foot is often termed the miserable malalignment syndrome and is seen more common in females. Treatment include strengthening the quadriceps and, in particular, the vastus medialis oblique can effectively reduce the Q-angle and prevents the lateral displacement of patella. A large quadriceps angle ( $\mathrm{Q}$-angle) is another frequently suggested contributing factor to Patello Femoral Pain Syndrome (PFPS). Patellofemoral Pain Syndrome, a clinical condition commonly found in athletes caused by weakening of Quadriceps muscles specifically VMO, increased Q-angle, overuse of the muscles and lateral retinaculum tightness.(5)

The Q-angle is influenced by a number of factors including the anatomy of the quadriceps and trochlear groove, the mechanics of the foot and the position of the tibial tubercle. The vastus medialis oblique muscles (VMO) of the quadriceps muscle group has been thought to be a major contributor to patella femoral joint pain. The VMO pulls the patella medially during knee extension and has been reported to fire later than the vastus lateralis (VL) in people with patellofemoral joint pain. This firing part may effect patellar tracking, causing the patella to track laterally because the VMO is not firing on time. Exercises that focus on VMO activity are emphasized to normalize the VMO:VL firing ratio to correct the patellar tracking pattern. Athletes with patellofemoral pain syndrome are frequently noted to have tight lateral knee retinaculum, tight hamstrings, patellar tracking abnormalities, a large Qangle and vastus medialis oblique (VMO) muscle atrophy. Treatment emphasizes VMO strengthening and hamstring stretching. The accurate determination of the $Q$ angle requires precise identification of the three bony landmarks used to measure it, even small differences in the placement of the center of Patella and Tibial tuberosity could alter the $Q$ angle greatly. (6)

\section{METHODS}

Research design adopted for this study was non-randomized, two group, Pre-test, Post-test assessment of Q-angle. The study was done as per the ethical guidelines formulated by the institutional ethical committee of Sri Lakshmi Narayana Institute of Medical Sciences, Puducherry, India. Twenty healthy young women of age 18 - 20 yrs were selected for the study. Purpose of the study, procedure, potential benefits and possible risk if participate were explained to all the participants, prior to the study and a written consent has obtained. Duration of the Study was 4 Weeks, 5 days/week, two sets/day, each set contains 10 times holding for about 10 seconds, rest period 5-I0 seconds. Participants were divided in to two groups of 10 each, GroupA- was given Isometric Quadriceps Activation (IQA) and Group B was given VMO strengthening.

\section{Isometric Quadriceps Activation (IQA) Procedure}

Members of Group A were instructed to lie in supine position with extended knee. A rolled (or) folded towel was placed under the right knee. Next the participants were instructed to press the towel hold it for about 10 seconds and then relax. The procedure was repeated 10 times.

\section{VMO Strengthening Procedure}

Members of Group B were also instructed to lie in supine position with extended knee. Participants were instructed to rotate their right 1 eg laterally. Followed to that they were told to raise the leg without bending the knee. Maintain the position for 10 seconds and then slowly lower the leg down. Relax and repeat the procedure for 10 times. Q-angle is measured using a Long-arm Goniometer (along with inch-tape $\&$ Scale- $30 \mathrm{~cm})$.

\section{Statistical Analysis}

In this study, difference in $\mathrm{q}$ angle before and after the treatment within the group is analyzed using unpaired' test and the difference between the groups were analyzed using unpaired ' $\mathrm{t}$ ' test with Welch's correction. Level of significance is $5 \%$. Data was analysed with GraphPad $\AA$ InStat 3 software. 
RESULTS

In the present study effect of isometric quadriceps activation and vastus medialis obliquus strengthening were analysed in healthy young females. The mean $\mathrm{q}$ angle before treatment was 21. (minimum 20 and maximum 23). While after the treatment, $\mathrm{q}$ angles were significantly reduced in both the groups and mean q angle was 16.3.

\begin{tabular}{|c|c|c|c|c|}
\hline & $\begin{array}{r}\text { Group A } \\
\text { Quadrice }\end{array}$ & $\begin{array}{l}\text { sometric } \\
\text { Activation }\end{array}$ & $\begin{array}{l}\text { Group } \\
\text { Streng }\end{array}$ & $\begin{array}{l}\text { - VMO } \\
\text { hening }\end{array}$ \\
\hline & IQA-Pre & IQA-Post & VMO-Pre & VMO-Post \\
\hline & 21 & 18 & 21 & 16 \\
\hline & 21 & 16 & 20 & 16 \\
\hline & 20 & 14 & 21 & 16 \\
\hline & 23 & 18 & 22 & 18 \\
\hline & 20 & 16 & 22 & 17 \\
\hline & 22 & 15 & 21 & 15 \\
\hline & 20 & 16 & 20 & 15 \\
\hline & 23 & 18 & 20 & 16 \\
\hline & 22 & 17 & 21 & 16 \\
\hline & 21 & 16 & 22 & 18 \\
\hline $\begin{array}{c}\text { Q-Angle } \\
\text { (Mean } \pm \text { SD) }\end{array}$ & $\begin{array}{r}21.3 \pm 1.16 \\
* * * p\end{array}$ & $\begin{array}{l}16.4 \pm 1.35 \\
0001\end{array}$ & $\begin{array}{r}21.3 \pm 0.81 \\
* * * \mathrm{p}\end{array}$ & $\begin{array}{l}16.3 \pm 1.059 \\
.0001\end{array}$ \\
\hline $\begin{array}{r}\text { Table 1. Effect } \\
\text { Oblique Stre }\end{array}$ & $\begin{array}{l}\text { ometric } Q u \\
\text { hening on } Q\end{array}$ & $\begin{array}{l}\text { riceps Acti } \\
\text { ngle of Fem } \\
\text { iparison }\end{array}$ & $\begin{array}{l}\text { ion and } \mathrm{Va} \\
\text { s-Pre anc }\end{array}$ & $\begin{array}{l}\text { tus Medialis } \\
\text { Post-Test }\end{array}$ \\
\hline $\begin{array}{l}\text { IQA- Pre- Isomet } \\
\text { IQA- Post- Isome } \\
\text { VMO- Pre- Vastu } \\
\text { VMO- Post- Vastu }\end{array}$ & $\begin{array}{l}\text { uadriceps Act } \\
\text { Quadriceps Ac } \\
\text { dialis Oblique } \\
\text { dialis Obliqu }\end{array}$ & $\begin{array}{l}\text { tion pre }- \text { tes } \\
\text { ation post }-t \\
\text { engthening } p \\
\text { rengthening }\end{array}$ & $\begin{array}{l}\text { st. } \\
\text { - test. }\end{array}$ & \\
\hline
\end{tabular}

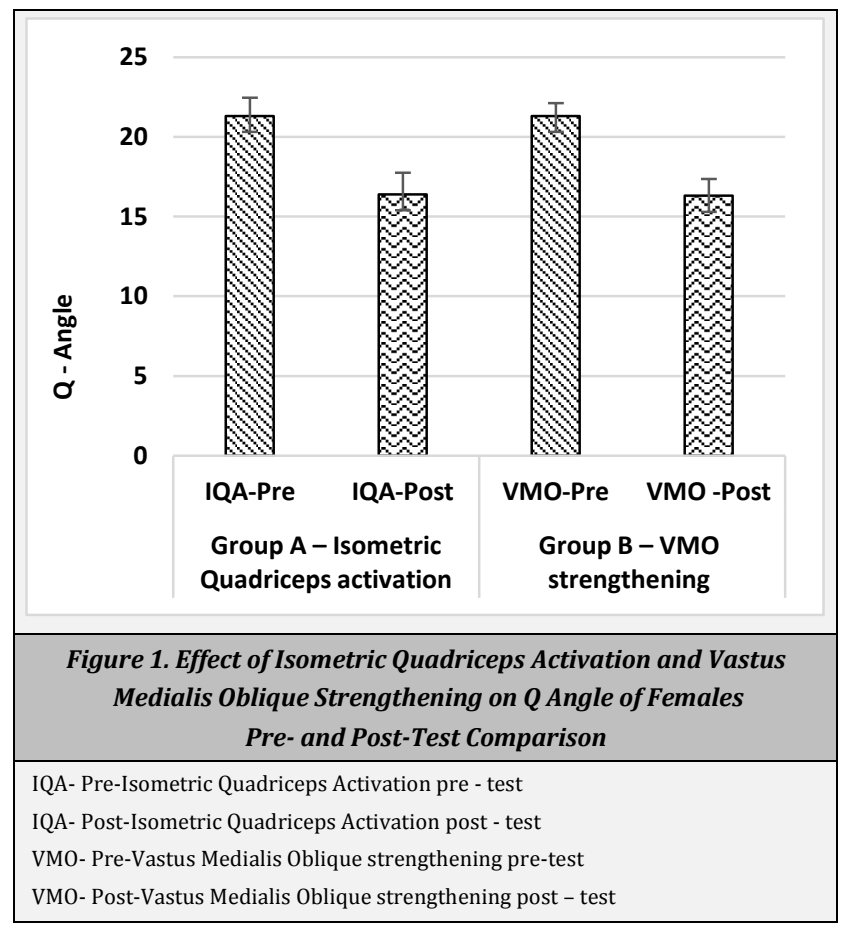

\section{DISCUSSION}

Q-angle is used to indicate the force vector acting on the patella and patellofemoral joint. Results of this study indicate that both isometric quadriceps activation and vastus medialis oblique strengthening can reduce the $Q$ angle significantly. The normal $Q$ angle in the non-treated females of the present population was 21. Even though both the treatment procedures could reduce the $Q$ angle to 16 ; significant statistical difference was not there between the procedures in reducing the $Q$ angle ( $p$ value - 0.4 ). Changes on the $Q$-angle are associated with chondromalacia patella, lateral dislocation of the patella, erosion of the patellar cartilage and of the lateral condyle, femoral internal rotation, foot pronation and internal tibial torsion.(7) The $\mathrm{Q}$ angle shows an inverse relationship with quadriceps strength, as the smallest the angle the greater the force produced by the quadriceps, which assumes that individuals with an increased $Q$ angle have weak quadriceps muscles and are more subject to diseases of the patellofemoral joint.(8)

Lathing house and Trimble ${ }^{(9)}$ suggested that an excessive Q-angle may predispose women to greater lateral displacement of the patella during vigorous activities and sports, in which the quadriceps muscle is stressed. According to Hettinger.(10) strength gain at $5 \%$ per week with one six second contraction per day at $67 \%$ maximal effort. He later concluded that maximal contraction produce better results. Van Eijden et al.,(11) stated that isometric exercise produces a greater amount of tension in the muscle than do concentric contraction. As suggested by His Lop,(12) 2/3 maximal contraction maintained for 6 second and performed daily, which increases strength in healthy females. Kauffman.(13) used more intensive training regimes, 2 sets of 10 maximum isometric contraction to test healthy young and older women. He found the young women (mean age of 22.6 years) gained $95 \%$ strength and old women (mean age of 69.2 years) gained $72 \%$. The difference in gain in strength between the two groups was not statistically significant.

Q-angle decreases with pronation of leg and increased internal rotation. The prolonged pronation of the foot requires compensation for the lack of external rotation of the tibia so the knee can extend properly. The femur internally rotates to make up for this lack of tibial external rotation and increases the force between the lateral patella and lateral femoral condyle.(14) As the tibia internally rotates with pronation, the femur internally rotates with greater exertion than the tibia, carrying the patella with it. This medial shift of the patella increases the Q- angle, causing excessive lateral pressure.(15) Hvid and Anderson(16) suggest that Q-angle may be most strongly associated with excessive hip internal rotation, which displaces the trochlear groove medially, leading to lateral malalignment of the patella. Lieb and Perry(17) stated that the distal fibers of $\mathrm{VMO}$ are angled approximately $55^{\circ}$ from the longitudinal axis of the femur. This increased angle gives mechanical advantage allowing the VMO proficient in preventing lateral patellar subluxation.

Increased patellofemoral joint stress and altered patellar tracking may increase the risk for PFP. Increase in $\mathrm{Q}$ angle in conditions like genu valgum, femoral ante version, external tibial torsion and subtalar joint pronation are associated with increased static patellofemoral joint stress. Quadriceps muscle weakness or imbalance with relative vastus medialis (VMO) weakness or imbalance in neuromuscular control of the VMO and vastus lateralis (VL) may cause PFP. The VMO is the weakest portion of the quadriceps, the first to atrophy with disuse and the last to rehabilitate. VMO weakness results in lateral shifting and tracking of the patella during the last $30^{\circ}$ of extension with resultant reduction in patellofemoral contact area and increased patellofemoral stress.(18) Sale ${ }^{(19)}$ reported that strength training programme of the muscles involved, depends not only on the quality and quantity of the muscles but also depends upon the nervous system to activate the muscles appropriately. 
Weakness of the VMO allows the patella to track too far laterally. The VMO is a major focus in the rehabilitation of patellofemoral pain; strengthening the VMO and improving the firing sequence with the VL are primarily concerns to correct the patellar tracking pattern. Also knee braces, specifically patellar braces, have been thought to help with this process. The patellofemoral knee brace places pressure on the lateral side of the patella to deter lateral movement. Treatment techniques frequently used include quadriceps exercises focusing on the VMO, patellar taping, electrical stimulation to guide quadriceps exercises, nonsteroidal anti-inflammatory agents, and patellofemoral knee braces.

A 2-cm lateral shift in the ASIS results in a 2 degree increase in Q-angle. Also a more medially placed patella and a shorter patellar tendon result in a larger Q-angle. Therefore, a large $\mathrm{Q}$-angle is more indicative of a medialized patella than a lateralized ASIS. Applying this reasoning to the mal tracking population, It can be theorized a large $Q$-angle is indicative of a medially placed patella under static conditions. This medial placement is a result of passive constraints alone because muscle activity is not present when the Q-angle is measured. For the non-lateral mal trackers (all but two of whom had a Qangle $>15$ degree), these passive constraints are capable of counteracting the lateral pull of the extensors during active contraction and maintaining a medialized patella.(20)

\section{CONCLUSIONS}

Many treatment procedures are available for the reduction of $\mathrm{q}$ angle and prevention of patellar displacement. Isometric quadriceps activation and vastus medialis oblique strengthening is cost effective and easy to administer. It can be used easily in a clinical and nonclinical setup. In the present study both these procedure were effective in reducing $Q$ angle significantly.

\section{REFERENCES}

[1] Austin WM. Women in Sports, Q Angle and ACL Injuries. Dynamic Chiropractic 2003;21(21). http://www.dynamicchiropractic.com/mpacms/dc/arti cle.php?id=9424

[2] Pagare V. Q Angle. http://www.physiopedia.com/\%27Q\%27_Angle\#cite_note-5

[3] Anh-Dung N, Boling MC, Levine B, et al. Relationships between lower extremity alignment and the quadriceps angle. Clin J Sport Med 2009;19(3):201-6.

[4] Wheeless CR, Nunley JA, Urbaniak JR. Q angle of the Knee. Orthopaedic References and Discussions for Physicians. http://www.wheelessonline.com/ortho/q_angle_of_the_ knee
[5] Miller JP, Sedory D, Croce RV. Leg rotation and vastus medialis oblique/vastus lateralis electromyogram activity ratio during closed chain kinetic exercises prescribed for patellofemoral pain. J Athl Train 1997;32(3):216-20.

[6] Raveendranath R, Nachiket S, Sujatha N, et al. Bilateral variability of the quadriceps angle ( $Q$ angle) in an adult Indian population. Iran J Basic Med Sci 2011;14(5):46571.

[7] Sanchez HM, De Morais SEG, Baraúna MA, et al. Evaluation of $Q$ angle in differents static postures. Acta Ortop Bras 2014;22(6):325-9.

[8] Livingston LA. The quadriceps angle: a review of the literature. J Orthop Sports Phys Ther 1998;28(2):105-9.

[9] Lathinghouse LH, Trimble MH. Effects of isometric quadriceps activation on the Q-angle in women before and after quadriceps exercise. J Orthop Sports Phys Ther 2000;30(4):211-6.

[10] Hettinger T. Physiology of strength. Springfield, Illinois, USA: Charles C Thomas Publisher 1961: p. 28-30. http://www.isometric-training.com/supportfiles/the_physiology_of_strength.pdf

[11] Van Eijden TM, De Boer W. A dynamometer for the measurement of the extension torque of the lower leg during static and dynamic contractions of the quadriceps femoris muscle. J Biomech 1983;16(12):1019-23.

[12] Hislop HJ. Quantitative changes in human muscular strength during isometric exercise. J Am Phys Ther Assoc 1963;43(1):21-38.

[13] Kauffman LT. Strength training effect in young and aged women. Arch Phys Med Rehabil 1985;66(4):223-6.

[14] Tiberio D. The effect of excessive subtalar joint pronation on patellofemoral mechanics: a theoretical model. J Orthop Sport Phys Ther 1987;9(4):160-5.

[15] D'Amico JC, Rubin M. The influence of foot orthoses on the quadriceps angle. J Am Podiatr Med Assoc 1986;76(6):337-40.

[16] Hvid I, Anderson LI. The Quadriceps angle and its relation to femoral torsion. Acta Orthop Scand 1982;53(4):577-9.

[17] Lieb FJ, Perry J. Quadriceps function: an anatomical and mechanical study using amputated limbs. J Bone Joint Surg Am 1968;50(8):1535-48.

[18] Houghton KM. Review for the generalist: evaluation of anterior knee pain. Pediatr Rheumatol Online J 2007;5:8.

[19] Sale DG. Neural adaptation to strength training. In: Strength and power in sport. $2^{\text {nd }}$ edn. 2008: p. 281-314. http://dx.doi.org/10.1002/9780470757215.ch15

[20] Sheehan FT, Derasari A, Fine KM, et al. Q-angle and J-sign: indicative of maltracking subgroups in patellofemoral pain. Clin Orthop Relat Res 2010;468(1):266-75. 